\title{
A novel multiobjective programming approach dealing with qualitative and quantitative objectives for environmental management
}

\author{
Ming-Lung Hung*, Wan-Fa Yang, Hwong-Wen Ma, Ya-Mei Yang \\ Graduate Institute of Environmental Engineering, National Taiwan University, 71 Chou-Shan Rd., Taipei 106, Taiwan, Republic of China
}

Received 30 September 2003; received in revised form 4 November 2004; accepted 7 March 2005

Available online 11 May 2005

\begin{abstract}
Environmental management problems are very complex and require considering numerous factors, such as environmental, economic, and social aspects. Qualitative and quantitative data always exist simultaneously in real world decision-making situations. A novel multiobjective programming approach is proposed in this study to solve qualitative and quantitative objectives for environmental management problems. This approach integrates the multiattribute and multiobjective decisionmaking methods and contains three main steps to solve the multiobjective programming problems, including formulation of the decision model, the alternatives prioritization by the fuzzy AHP method, and solving the model. A case study of food waste management conducted in Taiwan is used to demonstrate the practicality of this approach.
\end{abstract}

(C) 2005 Elsevier B.V. All rights reserved.

Keywords: Environmental management; Qualitative and quantitative objectives; Multiobjective programming; Fuzzy AHP; Food waste management

\section{Introduction}

Environmental management problems are very complex and require considering numerous factors. In environmental management problems, the decision-makers usually consider the environmental, economic, social and other factors (Morrissey and Browne, 2004). Some of these factors can be

\footnotetext{
* Corresponding author. Fax: +886223626373.

E-mail addresses: d89541004@ntu.edu.tw (M.-L. Hung), wfyang@ccms.ntu.edu.tw (W.-F. Yang), hwma@ccms.ntu.edu.tw (H.-W. Ma), cheryl@vunus.seed.net.tw. (Y.-M. Yang).
}

quantified, while others are qualitative at most. Multiobjective programming (MOP) is a popular method for solving problems with multiple considerations, such as locating sites, and choosing optimal environmental management alternatives/ strategies (Alidi, 1996; Chang and Hwang, 1996; Chang et al., 1996; Wen and Lee, 1998; Chang and Wei, 1999). However, MOP encounters difficulties in dealing with both qualitative and quantitative objectives in a decision problem. Actually, no previous studies have tried to apply the multiobjective programming to solve qualitative and quantitative objectives simultaneously. 
The purpose of this study is to develop a novel multiobjective programming approach by integrating the multiattribute and multiobjective decision-making methods to solve qualitative and quantitative objectives simultaneously for environmental management problems. An illustrative example will be provided to demonstrate the practicality of this approach.

The multiobjective programming that is commonly used is described in Section 2. We propose a new multiobjective programming approach in Section 3. The food waste management in the Taipei City is illustrated in Section 4. The result of the illustrating example is discussed in Section 5. In Section 6, some final remarks are made regarding the advantage of the proposed model.

\section{Multiobjective programming}

Multicriteria decision-making (MCDM) was developed in recent decades as a response to the problems faced by decision-makers when confronting complex environmental issues (Brown et al., 2001; Prato, 2003). Generally, MCDM can be divided into two categories (Hwang and Yoon, 1981): Multiattribute decision-making and multiobjective decision-making ((MODM), also known as multiobjective programming). MODM can further be divided into three parts based on information property: including non-preference, preference and interactive type. MADM can be divided into the outranking method and value or utility function based methods (Lahdelma et al., 2000). Some differences exist between these two methods: MADM is "attribute" in criteria definition while MODM is "objective"; the MADM is "passive" that it cannot treat constraints explicitly in a decision model while MODM is "active". The key difference is that MADM can cope with qualitative and quantitative data while MODM can only deal with quantitative data.

Generally, the multiobjective problem can be expressed as follows:

$$
\begin{aligned}
& \max (\text { or } \min ) Z(X) \\
& \quad=\left[z_{1}(X), z_{2}(X), \ldots, z_{k}(X), \ldots, z_{m}(X)\right] \\
& \text { s.t } X \in S
\end{aligned}
$$

where $Z(X)$ denotes the objective functions, $X$ represents the sets of decision variables, and $S$ represents the sets of constraints. The objective functions are separated into qualitative and quantitative categories: $z_{1}(X) \ldots z_{k}(X)$ have quantitative properties; in other words, the mathematical relationship can be built between $x$ and $z(X)$. However, $z_{k+1}(X) \ldots z_{m}(X)$ have qualitative properties where only ordinal relationship can be developed between $x$ and $z(X)$.

Using traditional MODM methods, the solution is obtained as follows:

$$
\begin{aligned}
& \max (\text { or } \min ) Z(X) \\
& \quad=\left[z_{1}(X), z_{2}(X), \ldots, z_{k}(X)\right] \quad \text { s.t } X \in S .
\end{aligned}
$$

The above solution is not the "real solution" because the $z_{k+1}(X) \ldots z_{m}(X)$ were not considered.

\section{A novel multiobjective programming approach}

This paper develops a novel methodology which integrates the MADM and MODM methods to solve mathematical programming problems including both qualitative and quantitative data. Fig. 1 displays the outline of this new algorithm. The main steps of this approach are described below.

\subsection{Formulate the model for environmental problems}

Real world environmental management problems require the consideration of numerous factors. For example, to consider environmental, economical, social aspects etc., we can formulate a multiobjective programming model that includes: decision variables, objective functions and constraints, concerning stakeholders. The stakeholders may consist of government, experts, NGOs, and business and so on.

\subsection{Prioritize the alternatives}

Many MADM methods are used to prioritize the alternatives, such as ELECTRE (Roy, 1991), PROMETHEE (Brans and Vincke, 1985), TOPSIS (Hwang and Yoon, 1981), and the AHP methods (Saaty, 1980). The AHP method was developed by Saaty (1980). However, for real world environmental management 


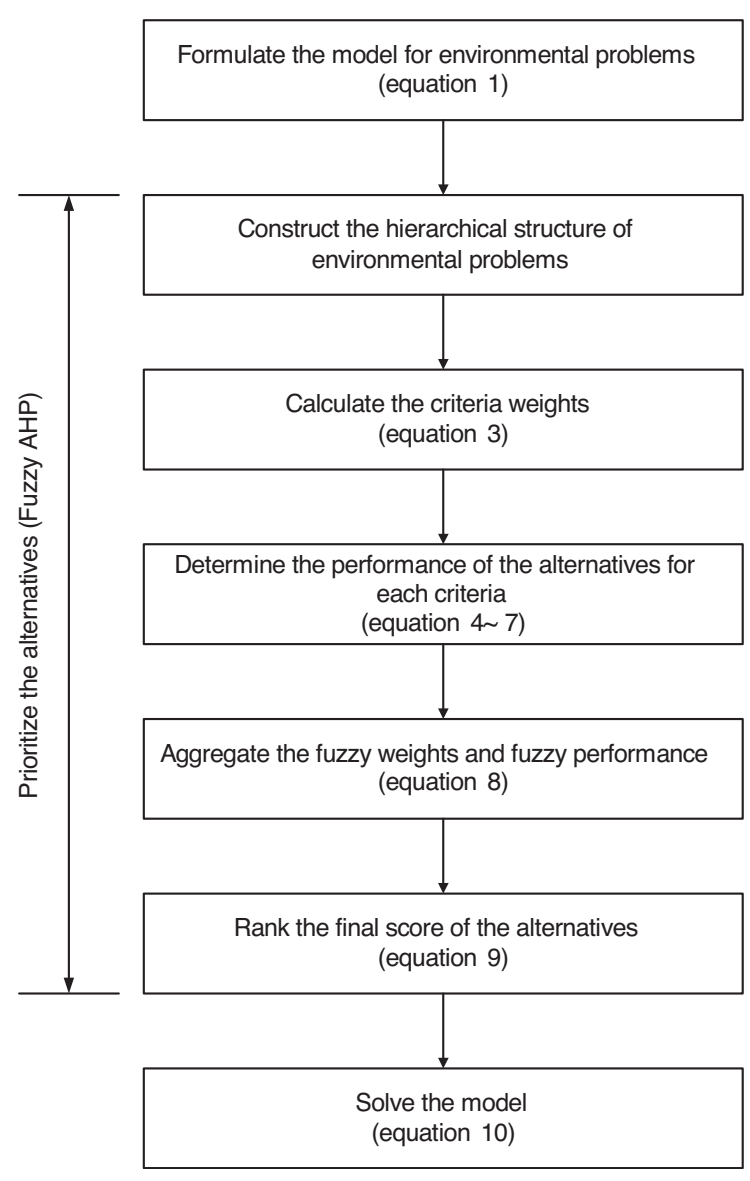

Fig. 1. The algorithm of the novel multiobjective programming approach.

problems that involve many stakeholders and conflicting viewpoints, the traditional AHP method is insufficient. Buckley (1985) applies the fuzzy theory to the AHP method to avoid neglecting extreme values. Applying the fuzzy AHP method involves five steps, as follows.

\subsubsection{Construct the hierarchical structure of the waste management problems}

In real MCDM problems, the process must be divided into distinct stages. First, based on a general problem statement, various stakeholders are defined and identified. They may include decision-makers, experts in relevant fields, and various interest groups affected by the decision. The overall objective is set during this stage. Next, the alternatives/strategies for a discrete MCDM problem comprising of a finite set of alternatives/strategies are assessed in terms of multiple criteria.

\subsubsection{Calculate the criteria weights}

The criteria weights can be determined by the stakeholders. To include all the options of the stakeholders, this study used the fuzzy weighting method. The fuzzy weights of the criteria can be determined as follows:

$$
\begin{aligned}
& \tilde{w}_{j}=\left[w_{j l}, w_{j m}, w_{j r}\right], \quad j=1 \sim m \\
& w_{j l}=\min \left\{w_{j k}\right\}, \forall j, \quad k=1 \sim p \\
& w_{j m}= \begin{cases}\operatorname{geomean}\left\{w_{j k}\right\}, \forall j, k & \text { if all } w_{k j} \neq 0 \\
\operatorname{ave}\left\{w_{j k}\right\}, \forall j, k & \text { otherwise }\end{cases} \\
& w_{j r}=\max \left\{w_{j k}\right\}, \forall j, k
\end{aligned}
$$

where $m$ denotes number of criteria, $p$ represents number of experts, $w_{j k}$ is the weight of criteria $j$ as judged by expert $k, w_{j l}$ denotes the minimum weight of criteria $j$ as judged by all of the experts, $w_{j m}$ represents the geomean (or average) weight of criteria $j$ as judged by all the experts, and $w_{j r}$ is the maximum weight of criteria $j$ as judged by all the experts.

\subsubsection{Determine the fuzzy performance of the alter- natives for each criteria}

The criteria can be divided into two categories: quantitative and qualitative, as noted earlier. The calculation of performance of the alternatives criteria can be calculated as follows.

3.2.3.1. Quantitative criteria. This investigation utilizes the triangular fuzzy number to express the performance of quantitative criteria. First, the original value of the quantitative criteria is normalized and expressed as follows:

$$
x_{i j}^{\mathrm{norm}}=\frac{x_{j}^{\max }-x_{i j}^{0}}{x_{j}^{\max }-x_{j}^{\min }}, \quad i=1 \sim n(\text { positive criteria) }
$$

$$
x_{i j}^{\mathrm{norm}}=\frac{x_{i j}^{0}-x_{j}^{\min }}{x_{j}^{\max }-x_{j}^{\min }}, \quad i=1 \sim n(\text { negative criteria })
$$


where $n$ denotes the number of alternatives, $x_{i j}^{\text {norm }}$ represents the normalized value of criteria $j$ for alternative $i, x_{i j}^{0}$ is the original value of criteria $j$ for alternative $i, x_{j}^{\max }$ denotes the maximum value of criteria $j$ for all alternatives, and $x_{j}^{\min }$ represents the minimum value of criteria $j$ for all alternatives. The positive criteria means that those criteria positively affect environmental management, e.g. the social acceptability of the treatment technologies, and the negative criteria are the criteria that negatively affect environmental management, e.g. the cost of the treatment technologies.

Second, the normalization value is fuzzified using the following equation:

fuzzy performance of quantitative criteria $\tilde{x}_{i j}$

$$
=\left(0.9 \cdot x_{i j}^{\mathrm{norm}}, x_{i j}^{\mathrm{norm}}, \min \left(1.1 \cdot x_{i j}^{\mathrm{norm}}, 1\right)\right) \text {. }
$$

3.2.3.2. Qualitative criteria. The linguistic variables are designed to express the words or sentences in a natural or artificial language. The linguistic variables is composed of five variables $(v, T, X, g, m)$, where: $v$ denotes the name of the variable, $T$ represents the set of linguistic terms of $v$ that refers to a base variable whose values range over universal set $X, g$ is a syntactic rule for generating linguistic terms, and $m$ denotes a semantic rule that is assigned to each linguistic term (Zimmermann, 1987). The linguistic variables are utilized to calculate the performance of the qualitative criteria. Five levels are used to integrate the preference of the relative field experts, as shown in Fig. 2. The fuzzy performance of qualitative criteria is determined by using a fuzzy triangular number and is expressed as follows:

fuzzy performance of qualitative criteria $\tilde{x}_{i j}$

$$
\begin{aligned}
& =\left[x_{i j 1}, x_{i j \mathrm{~m}}, x_{i j \mathrm{r}}\right] \\
x_{i j \mathrm{l}} & =\min \left\{x_{i j k}^{1}\right\}, \forall j, k \\
x_{i j \mathrm{~m}} & =\operatorname{geomean}\left\{x_{i j k}^{\mathrm{m}}\right\}, \forall j, k \\
x_{i j \mathrm{r}} & =\max \left\{x_{i j k}^{\mathrm{r}}\right\}, \forall j, k
\end{aligned}
$$

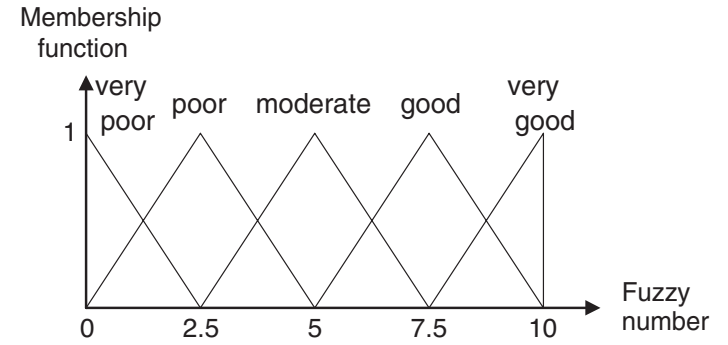

Fig. 2. Linguistic variables for determining the qualitative criteria.

where $x_{i j 1}$ denotes the left value of the fuzzy number of qualitative criteria $j$ for the alternatives $i, x_{i j \mathrm{~m}}$ represents the medium value of the fuzzy number of qualitative criteria $j$ for the alternatives $i, x_{i j \mathrm{r}}$ is the right value of the fuzzy number of qualitative criteria $j$ for the alternatives $i, x_{i j k}$ denotes the left value of the fuzzy number of qualitative criteria $j$ as judged by expert $k$ for the alternatives $i, x_{i j k} \mathrm{~m}$ represents the medium value of the fuzzy number of qualitative criteria $j$ as judged by expert $k$ for the alternatives $i$, and $x_{i j k}{ }^{\mathrm{r}}$ denotes the right value of the fuzzy number of qualitative criteria $j$ as judged by expert $k$ for the alternatives $i$.

\subsubsection{Aggregate the fuzzy weights and fuzzy performance}

The simple additive method is utilized to aggregate the fuzzy weights and fuzzy performance, i.e.,

$$
\begin{aligned}
\tilde{\mathbf{R}} & =\tilde{\mathbf{X}} \otimes \tilde{\mathbf{W}}^{T}=\tilde{x}_{i j} \otimes \tilde{\mathbf{W}}^{T} \\
& =\left(\begin{array}{l}
\tilde{x}_{11} \cdots \tilde{x}_{1 m} \\
\vdots \\
\vdots \\
\tilde{x}_{n 1} \cdots \\
\cdots \\
\tilde{x}_{n m}
\end{array}\right) \otimes\left[\begin{array}{l}
\tilde{w}_{1} \\
\vdots \\
\tilde{w}_{m}
\end{array}\right] \\
& =\left(\begin{array}{l}
\tilde{x}_{11} \otimes \tilde{w}_{1} \oplus \tilde{x}_{12} \otimes \tilde{w}_{2} \oplus \cdots \oplus \tilde{x}_{1 m} \otimes \tilde{w}_{m} \\
\vdots \\
\tilde{x}_{n 1} \otimes \tilde{w}_{1} \oplus \tilde{x}_{n 2} \otimes \tilde{w}_{2} \oplus \cdots \oplus \tilde{x}_{n m} \otimes \tilde{w}_{m}
\end{array}\right)
\end{aligned}
$$

where $\tilde{\mathbf{R}}$ denotes fuzzy evaluation matrix, $\tilde{\mathbf{X}}$ presents fuzzy performance matrix, and $\tilde{\mathbf{W}}$ is fuzzy weighting matrix.

\subsubsection{Rank the final score of the alternatives}

The centralized weights method (Yager, 1980) is the most commonly used defuzzification method (Opricovic and Tzeng, 2003) and is used in this study to defuzzify the fuzzy numbers to prioritize the alternatives. This method converts a fuzzy number into crisp value based on the concept of the center-of- 
gravity. For the triangular fuzzy number $\tilde{F}=\left(f_{1}, f_{\mathrm{m}}, f_{\mathrm{r}}\right)$ and the crisp value of the fuzzy number can be expressed as follows:

$F_{\text {crisp }}=f_{1}+\left[\left(f_{\mathrm{m}}-f_{1}\right)+\left(f_{\mathrm{r}}-f_{1}\right)\right] / 3$

\subsection{Solving the model}

Next, the ranking results are utilized to solve the original mathematical programming problems. The best alternatives will be set as maximum as possible. The original problem then is transformed to the following model:

$$
\begin{aligned}
& \text { Step (1) } \\
& \max x_{1}^{\mathrm{r}} \\
& \text { s.t } \quad X \in S \\
& \text { Step (2) } \\
& \max x_{2}^{\mathrm{r}} \\
& \text { s.t } \quad X \in S \\
& x_{1}^{\mathrm{r}}=x_{1}^{\mathrm{r}^{*}} \\
& \vdots
\end{aligned}
$$

$$
\begin{aligned}
& \text { Step }(n) \\
& \max x_{n}^{\mathrm{r}} \\
& \text { s.t } \quad X \in S \\
& x_{1}^{\mathrm{r}}=x_{1}^{\mathrm{r}^{*}} \\
& x_{2}^{\mathrm{r}}=x_{2}^{\mathrm{r}^{*}} \\
& \vdots \\
& x_{n-1}^{\mathrm{r}}=x_{n-1}^{\mathrm{r}^{*}}
\end{aligned}
$$

where $x_{1}^{\mathrm{r}}$ denotes the decision variable which is ranked first in the previous procedure, $x_{2}^{\mathrm{r}}$ represents the decision variable which is ranked second, $\ldots, x_{n}^{\mathrm{r}}$ denotes the decision variable which is ranked $n$ th. $x_{1}^{\mathrm{r}^{*}}$ is the optimal solution for $x^{\mathrm{r}^{*}}$ in Step (1), $x_{2}^{\mathrm{r}^{*}}$ is the optimal solution for $x_{2}^{\mathrm{r}}$ in Step (2) and so on. Finally, the model can be solved simply.

\section{Case study}

The newly developed multiobjective programming approach is used to evaluate a hypothetical food waste management problem in Taipei City, Taiwan. Some of the data used in this study are assumed, but some are based on real life situations. The density of the population of Taipei City is highest in Taiwan. Food waste as defined here includes household kitchen waste, and residual food from restaurants, markets and schools. The quantity of food waste is about $40 \%$ of the municipal solid waste (MSW) in Taipei. Total food waste generated in Taipei City is 1316 tons/day. If the food waste is recycled, then the amount of MSW will decrease significantly.

The algorithm of finding the optimal food waste management schemes is as follows.

\subsection{Formulate the model for environmental problems}

\subsubsection{Decision variables}

This study considers five different technologies related to food waste treatment, including incineration (INC), landfill (LAN), composting (COM), hog feeding (HOG), and anaerobic digestion (ANA). The decision variables are:

$X_{1}$ (tons/day): the amount of food waste treatment for incineration.

$X_{2}$ (tons/day): the amount of food waste treatment for landfilling.

$X_{3}$ (tons/day): the amount of food waste treatment for composting.

$X_{4}$ (tons/day): the amount of food waste treatment for hog feeding.

$X_{5}$ (tons/day): the amount of food waste treatment for anaerobic digestion.

\subsubsection{Objective functions}

This study considers four objectives, namely; environmental, economic, social, and technological 
factors. Environmental factors involve human health, resource consumption and ecological impacts. Economic factors include system costs, system benefits and the marketing potential of the byproducts. The social factors comprise of social justice, social welfare and social acceptability and technological factors include land demand and technology maturity. The objective functions are defined as follows:

$Z_{1}(\mathrm{mPt} / \mathrm{ton})=$ the objective function of human health.

$Z_{2}(\mathrm{mPt} / \mathrm{ton})=$ the objective function of resource consumption.

$Z_{3}(\mathrm{mPt} / \mathrm{ton})=$ the objective function of ecological impacts.

$Z_{4}(\mathrm{NT} \$ /$ ton $)=$ the objective function of the system cost.

$Z_{5}(\mathrm{NT} \$ /$ ton $)=$ the objective function of the system benefit.

$Z_{6}=$ the objective function of the marketing potential.

$Z_{7}=$ the objective function of social justice.

$Z_{8}=$ the objective function for social welfare.

$Z_{9}=$ the objective function for social acceptability.

$Z_{10}($ ha/ton $)=$ the objective function for land demand.

$Z_{11}=$ the objective function for the maturity of the technology.

The objectives can be divided into two categories: qualitative and quantitative, based on the property of the data of the objective functions. The quantitative part includes $Z_{1} \sim Z_{5}$ and $Z_{10}$, while the qualitative part consists of $Z_{6} \sim Z_{9}$ and $Z_{11}$. The environmental, economic, and physical data for food waste management must be integrated together to complete the formulation of the quantitative objective function. The performance on environmental objective $\left(Z_{1}, Z_{2}, Z_{3}\right)$ was determined by life cycle assessment with the eco-indicator 99 calculated using SimaPro 5.1 (Product Ecology Consultants, 2002). The performance on economic and technological objectives $\left(Z_{4}, Z_{5}, Z_{10}\right)$ was calculated using the data from the Bureau of Environmental Protection of Taipei City (Yang et al., 2002). The system cost contains the construction and operating cost, and the system benefit is defined as the profit from the treatment units. The qualitative objectives cannot be determined using mathematical formula, and are discussed later; however, the quantitative objective functions can be determined as follows:

$\min Z_{i}=C_{i j} \bullet X_{j} \quad \forall i=1,2,3,4,10 ; \quad j=1 \sim 5$

$\max Z_{i}=C_{i j} \bullet X_{j} \quad \forall i=5 ; \quad j=1 \sim 5 \quad(11-16)$

where $C_{i j}$ denote the coefficients of the objective function.

\subsubsection{Constraints}

The constraints in this model are described as follows

4.1.3.1. Mass balance constraint. Since the sum of the five alternatives should equal the food waste generation, it can be shown that

$\sum_{j=1}^{5} X_{j}=X$

4.1.3.2. Capacity constraint. An alternative $j$ can provide up to $b_{j}$ units which should be equal or less than its capacity. Taipei City contains three incinerators and one landfill, and the capacity of all the incinerators is 4200 tons/day, while that of the landfill is 500 tons/day.

$X_{j} \leq b_{j}, \quad j=1,2$.

4.1.3.3. Market demand constraint. The byproducts identified in this study are the products transformed from the food waste using the treatment technologies. For example, the byproduct of the INC and COM is power and soil conditioner respectively. No marketing limitations exist for the byproducts of the treatment technology, with the exception of composting. The market potential of the byproducts of the treatment technology is limited because of the landscape capacity in Taipei City, and it is about 20,000 tons/ year (Yang et al., 2002).

$T_{\text {com }} \cdot X_{3} \leq M_{\text {com }}$

where $T_{\text {com }}$ denotes the transforming rate of food waste using the composting treatment technology, 
$M_{\text {com }}$ represents the market demand of the byproduct of food waste using the composting treatment technology.

4.1.3.4. Separation rate constraint. The separation rate is the ratio of the amount of food waste collected divided by the amount of food waste generated. If food waste is not separated and it would not be subject to treatment (e.g. COM, HOG, ANA). So separation rate is important in food waste management. The separation rate is affected by environmental education, legislation, economic incentives, technological factors, and so on, and is assumed to be $30 \%$.

$X_{3}+X_{4}+X_{5} \leq R \cdot X$

where $R$ denotes the separation rate of food waste.
4.1.3.5. Nonnegative constraint.

All $X_{j} \geq 0, \quad j=1 \sim 5$.

\subsection{Prioritize the alternatives}

The fuzzy AHP approach was used to prioritize the alternatives and described as follows.

4.2.1. Build the hierarchical structure of the waste problems

The hierarchy of the problems can be established by classifying the objective functions mentioned before, as shown in Fig. 3.

\subsubsection{Calculate the criteria weights}

The criteria weights are determined by the questionnaires to reflect the opinion of the stakeholders

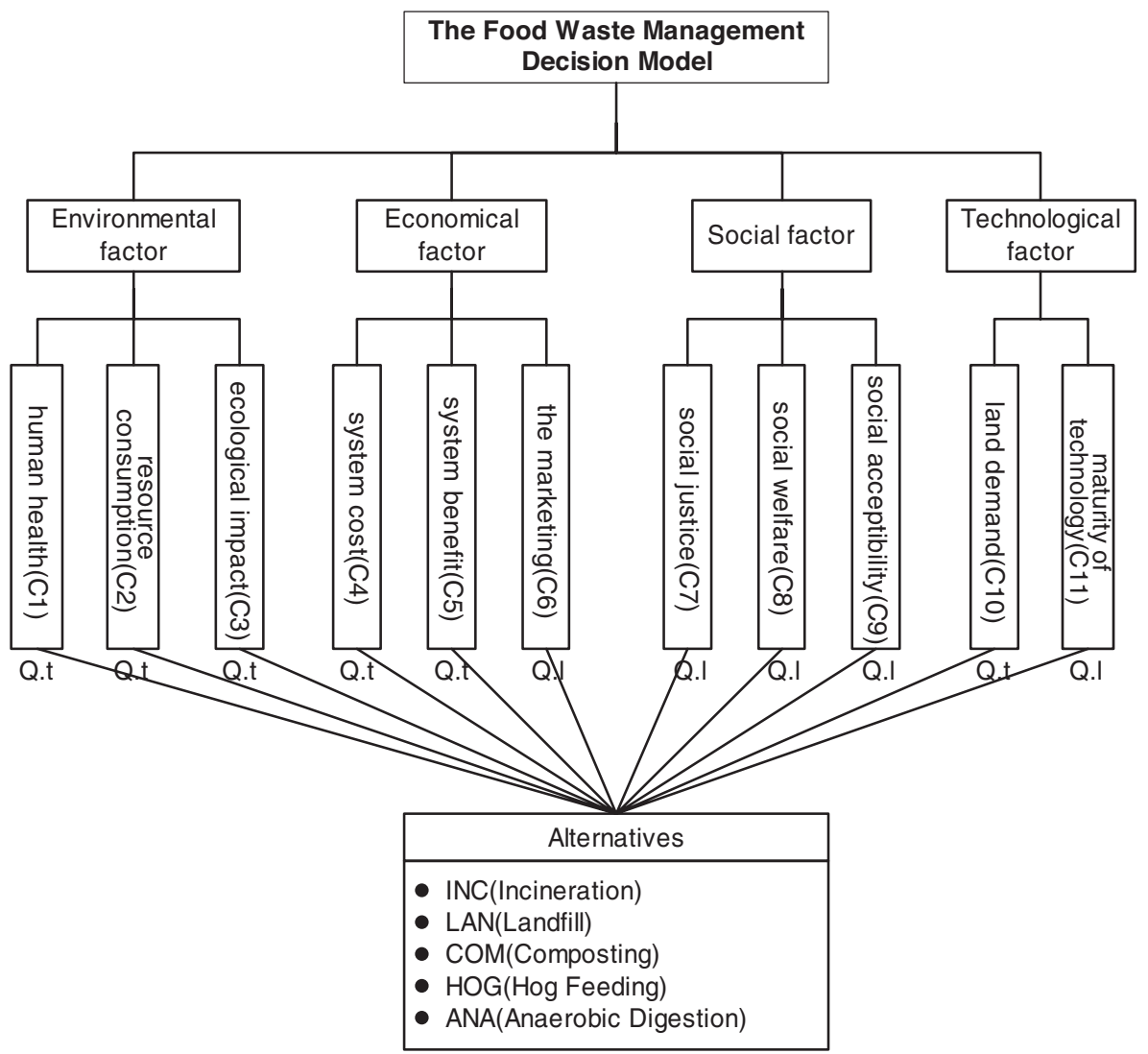

Q.t:quantitative Q.I:qualitative

Fig. 3. Fuzzy AHP hierarchy of food waste management problems. 
Table 1

Fuzzy criteria weights for evaluating food waste management

\begin{tabular}{lc}
\hline Criteria & Fuzzy criteria weights \\
\hline C1 & $(0.016,0.148,0.481)$ \\
C2 & $(0.012,0.062,0.277)$ \\
C3 & $(0.026,0.134,0.481)$ \\
C4 & $(0.004,0.026,0.179)$ \\
C5 & $(0.004,0.042,0.257)$ \\
C6 & $(0.005,0.047,0.298)$ \\
C7 & $(0.006,0.065,0.280)$ \\
C8 & $(0.004,0.025,0.177)$ \\
C9 & $(0.006,0.053,0.288)$ \\
C10 & $(0.008,0.060,0.504)$ \\
C11 & $(0.011,0.051,0.529)$ \\
\hline
\end{tabular}

(including: government, experts, NGOs and business). The priorities assigned to each criterion by these stakeholders are integrated to develop the fuzzy criteria weights, as shown in Table 1.

\subsubsection{Determine the performance of the alternatives for each criteria}

The performance of the alternatives for quantitative criteria is determined by Eq. (6). The triangular fuzzy number is utilized to express the performance of quantitative criteria $(\mathrm{C} 1, \mathrm{C} 2, \mathrm{C} 3, \mathrm{C} 4, \mathrm{C} 5, \mathrm{C} 10)$. The linguistic variables are used to calculate the performance of the qualitative criteria (C6, C7, C8, C9, C11). Table 2 displays the fuzzy performance of all criteria.

\subsubsection{Aggregate the fuzzy weights and fuzzy perform-} ance and ranking the final score of the alternatives

The fuzzy weighting and fuzzy performance can be aggregated to obtain the final score of the alternatives using Eq. (8). Fig. 4 shows the final result of food

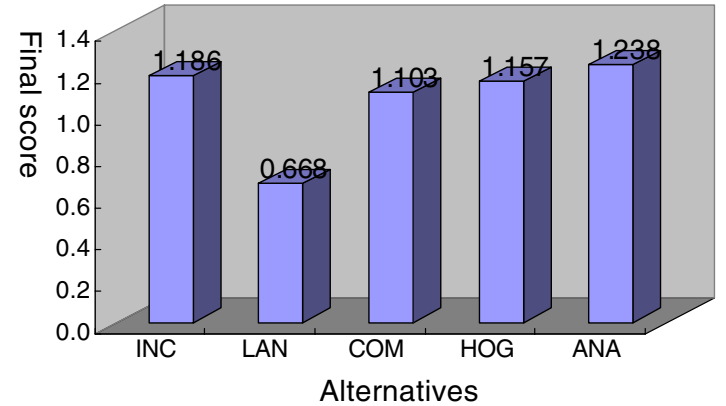

Fig. 4. Final score of the alternatives for food waste management.

waste management. The food waste management alternatives are ranked as follows:

$A N A \succ I N C \succ H O G \succ C O M \succ L A N$

\subsection{Solve the model}

Next, the multiobjective model can be solved using Eq. (10). Because ANA is the best alternative in this study, the amount of ANA is as maximal as possible until the limitation is reached. The INC is better than other technologies exception for ANA, and the amount of INC is also as maximal as possible until the limitation is reached. The final results are: $\mathrm{INC}=921$ tons/day, $\mathrm{LAN}=0$ ton/day, $\mathrm{COM}=0$ ton/day, $\mathrm{HOG}=0$ ton/day, $\mathrm{ANA}=395$ tons/ day.

\section{Discussion}

In this study, the final scores of the alternatives are close exceptions for LAN. The final solution of

Table 2

Fuzzy performance of food waste management

\begin{tabular}{llllll}
\hline Criteria & INC & LAN & COM & HOG & ANA \\
\hline C1 & $(0.439,0.488,0.537)$ & $(0.200,0.222,0.244)$ & $(0.000,0.000,0.000)$ & $(0.845,0.939,1.000)$ & $(0.900,1.000,1.000)$ \\
C2 & $(0.728,0.809,0.890)$ & $(0.000,0.000,0.000)$ & $(0.567,0.630,0.693)$ & $(0.900,1.000,1.000)$ & $(0.749,0.832,0.915)$ \\
C3 & $(0.798,0.887,0.976)$ & $(0.000,0.000,0.000)$ & $(0.748,0.831,0.914)$ & $(0.900,1.000,1.000)$ & $(0.809,0.899,0.988)$ \\
C4 & $(0.375,0.416,0.458)$ & $(0.000,0.000,0.000)$ & $(0.900,1.000,1.000)$ & $(0.247,0.274,0.302)$ & $(0.220,0.244,0.269)$ \\
C5 & $(0.016,0.018,0.020)$ & $(0.000,0.000,0.000)$ & $(0.002,0.002,0.002)$ & $(0.900,1.000,1.000)$ & $(0.061,0.068,0.075)$ \\
C6 & $(0.000,0.446,1.000)$ & $(0.000,0.450,1.000)$ & $(0.250,0.623,1.000)$ & $(0.000,0.602,1.000)$ & $(0.000,0.542,1.000)$ \\
C7 & $(0.250,0.612,1.000)$ & $(0.250,0.500,0.750)$ & $(0.250,0.612,1.000)$ & $(0.000,0.125,0.500)$ & $(0.250,0.500,0.750)$ \\
C8 & $(0.000,0.250,0.500)$ & $(0.000,0.250,0.500)$ & $(0.500,0.866,1.000)$ & $(0.000,0.354,0.750)$ & $(0.000,0.433,1.000)$ \\
C9 & $(0.250,0.707,1.000)$ & $(0.000,0.250,0.500)$ & $(0.250,0.612,1.000)$ & $(0.000,0.433,1.000)$ & $(0.250,0.612,1.000)$ \\
C10 & $(0.900,1.000,1.000)$ & $(0.678,0.754,0.829)$ & $(0.878,0.976,1.000)$ & $(0.000,0.000,0.000)$ & $(0.890,0.989,1.000)$ \\
C11 & $(0.500,0.794,1.000)$ & $(0.250,0.692,1.000)$ & $(0.000,0.472,1.000)$ & $(0.250,0.588,1.000)$ & $(0.000,0.379,0.750)$ \\
\hline
\end{tabular}


this case study is unexpectedly since the ranking of $\mathrm{COM}$ is the fourth. This is because COM is a pilot plant and other alternatives are full-scale facilities. The food waste needs to be separated prior to be treated by ANA and this situation restricts the magnitude of ANA, so the value of ANA is only 395 tons/day although it is the best alternatives.

The problem solution is limited by some constraints when the alternatives are ordered and the situation appears the same as in the real world. Ranking of the alternatives enables the best alternatives to be selected. However, some limitations always exist regarding the best alternatives. This shows that the ranking the results of the alternatives is very important, and thus the ranking can be determined by "sensitivity analysis", or alternatively the results can be confirmed by the decision-makers and stakeholders.

\section{Conclusions}

Although multiobjective programming is a popular method for solving numerous environmental management problems, it encounters difficulty in solving qualitative and quantitative objectives simultaneously. Unfortunately the realistic environmental problems often require the consideration of both qualitative and quantitative objectives. MADM methods can be used to solve environmental problems with qualitative and quantitative criteria, but the limitation of these methods is their passive property in dealing with constraints in environmental management problems. There are also numerous applications of combined MOP and MADM methods for solving environmental management problems, but the purpose of these methods is to evaluate the priorities of goals and weights of decision variables. These methods cannot solve qualitative and quantitative objectives simultaneously. The novel multiobjective programming approach presented here provides a useful tool for solving real world environmental management problems. This approach can solve the problems involving both quantitative and qualitative objectives, and can overcome the problem of the traditional multiobjective programming being unable to deal with the qualitative data in the model. The approach presented here can be applied to solving environmental management (e.g. air, waste, water etc.,) and other decision-making problems.

\section{Acknowledgement}

The authors would like to thank the Bureau of Environmental Protection of Taipei City, Taiwan for financially supporting this research.

\section{References}

Alidi, A.S., 1996. A multiobjective optimization model for the waste management of the petrochemical industry. Applied Mathematical Modelling 20, 925-933.

Brans, J.P., Vincke, Ph., 1985. A preference ranking organization method (The PROMETHEE Method for MCDM). Management Science 31, 647-656.

Brown, K., Adger, W.N., Tompkins, E., et al., 2001. Trade-off analysis for marine protected area management. Ecological Economics 37, 417-434.

Buckley, J.J., 1985. Fuzzy hierarchical analysis. Fuzzy Sets and System 17, 233-247.

Chang, C.T., Hwang, J.R., 1996. A multiobjective programming approach to waste minimization in the utility systems of chemical processes. Chemical Engineering Science 51, $3951-3965$.

Chang, N.B., Wei, Y.L., 1999. Strategic planning of recycling dropoff stations and collection network by multiobjective programming. Environmental Management 24, 247-263.

Chang, N.B., Wen, C.G., Chen, Y.L., 1996. A grey fuzzy multiobjective programming approach for the optimal planning of a reservoir watershed: B. Application. Water Research 30 , $2335-2340$

Hwang, C.L., Yoon, K., 1981. Multiple Attribute Decision Making: Methods and Applications. Springer-Verlag, Berlin.

Lahdelma, R., Salminen, P., Hookkanen, J., 2000. Using multicriteria methods in environmental planning and management. Environmental Management 26, 595-605.

Morrissey, A.J., Browne, J., 2004. Waste management models and their application to sustainable waste management. Waste Management 24, 297-308.

Opricovic, S., Tzeng, G.H., 2003. Defuzification within a multicriteria decision model. International Journal of Uncertainty, Fuzziness and Knowledge-Based Systems 11, 635-652.

Prato, T., 2003. Multiple-attribute evaluation of ecosystem management for the Missouri River system. Ecological Economics 45 , 297-309.

Product Ecology Consultants, 2002. SimaPro 5.1 User Manual. PréConsultants, Amersfoort, The Netherlands.

Roy, B., 1991. The outranking approach and the foundations of ELECTRE methods. Theory and Decision 31, 49-73. 
Saaty, T.L., 1980. The Analytic Hierarchy Process. McGraw-Hill, New York.

Wen, C.G., Lee, C.S., 1998. A neural network approach to multiobjective optimization for water quality management in a river basin. Water Resources Research 34, 427-436.

Yager, R.R., 1980. On a general class of fuzzy connectives. Fuzzy Sets and Systems 4, 235-242.
Yang, W.F., et al., 2002. The study of hazardous composition of the food waste and its byproduct and the strategy planning of food waste management. Bureau of Environmental Protection of Taipei City, Taiwan.

Zimmermann, H.J., 1987. Fuzzy Sets, Decision Making, and Expert Systems. Kluwer Academic, Boston. 